\title{
Behavioral interactions of simvastatin and fluoxetine in tests of anxiety and depression
}

This article was published in the following Dove Press journal:

Neuropsychiatric Disease and Treatment

28 September 2012

Number of times this article has been viewed

\author{
Tainaê Santos' \\ Monaliza Marizete \\ Baungratz' \\ Suellen Priscila Haskel ${ }^{2}$ \\ Daniela Delwing de Lima $^{3}$ \\ Júlia Niehues da $\mathrm{Cruz}^{4}$ \\ Débora Delwing Dal \\ Magro 5 \\ José Geraldo Pereira da \\ Cruz $^{5}$ \\ 'Department of Medicine, \\ ${ }^{2}$ Department of Physiotherapy, \\ Regional University of Blumenau, \\ Santa Catarina, Brazil; ${ }^{3}$ Department \\ of Pharmacy, University of Joinville \\ Region, Santa Catarina, Brazil; \\ ${ }^{4}$ Department of Medicine, University \\ of the Extreme South of Santa \\ Catarina, Santa Catarina, Brazil; \\ ${ }^{5}$ Department of Natural Sciences, \\ Regional University of Blumenau, \\ Santa Catarina, Brazil
}

Correspondence: José Geraldo Pereira da Cruz

Department of Natural Sciences,

Universidade Regional de Blumenau,

Rua Antônio da Veiga, I40, 890I2900,

Blumenau, Santa Catarina, Brazil

Tel +55047 332I 0272

Fax +5504733210233

Email jgcruz@furb.br

\begin{abstract}
Simvastatin inhibits 3-hydroxy-3-methylglutaryl CoA reductase, the rate-limiting enzyme in the cholesterol biosynthetic pathway, and is widely used to control plasma cholesterol levels and prevent cardiovascular disease. However, emerging evidence indicates that the beneficial effects of simvastatin extend to the central nervous system. The effects of simvastatin combined with fluoxetine provide an exciting and potential paradigm to decreased anxiety and depression. Thus, the present paper investigates the possibility of synergistic interactions between simvastatin and fluoxetine in models of anxiety and depression. We investigated the effects of subchronically administered simvastatin ( 1 or $10 \mathrm{mg} / \mathrm{kg} /$ day) combined with fluoxetine ( 2 or $10 \mathrm{mg} / \mathrm{kg}$ ) at 24, 5, and 1 hour on adult rats before conducting behavioral tests. The results indicate that simvastatin and/or fluoxetine treatment reduces anxiety-like behaviors in the elevated plus-maze and open-field tests. Our results showed that simvastatin and/or fluoxetine induced a significant increase in the swimming activity during the forced swimming test (antidepressant effect), with a concomitant increase in climbing time in simvastatin-treated animals only (noradrenergic activation). We hypothesize that anxiolytic and antidepressant effects of simvastatin and/or fluoxetine produce their behavioral effects through similar mechanisms and provide an important foundation for future preclinical research.
\end{abstract}

Keywords: elevated plus-maze, fluoxetine, forced swimming test, open-field, simvastatin

\section{Introduction}

Clinically, simvastatin has been widely used to reduce serum low density lipoprotein cholesterol by inhibiting the rate-limiting enzyme hydroxymethylglutaryl-coenzyme reductase. In addition, evidence shows that simvastatin reduces the risk of ischemic heart disease events and cerebrovascular stroke and has potential applications in multiple sclerosis, traumatic brain injury, Alzheimer's disease, and anxiety. ${ }^{1-4}$ Despite growing evidence for the role of simvastatin in central nervous system diseases, there is relatively little knowledge of its direct psychoneurological impacts on central receptors and its association with behavioral effects.

The first evidence, indicating the effects of simvastatin treatment on N-methylD-aspartate (NMDA) receptor binding density in the brain reveals a possible NMDA antagonist-like effect, which provides an exciting and potential paradigm to decreased anxiety. ${ }^{4}$ This study showed that compared with the saline group, treatment of male Sprague-Dawley rats with simvastatin at a high dose $(10 \mathrm{mg} / \mathrm{kg} /$ day $)$ produced a significant longer traveled distance and higher average velocity in an open-field arena, suggesting hyperlocomotive activity, while increased time traveled in the open arms in an elevated plus-maze was also observed, reflecting reduced anxiety-like behavior. ${ }^{4}$ 
The prolonged administration of different classes of drugs may produce convergent effects on different neurotransmitter systems or signaling targets. Unfortunately, little information is available regarding neurotransmitter substrates that are critical for the behavioral effects of different types of drugs in animal models. In addition, data accumulated in the last decade indicate that NMDA receptors may be involved in the pathophysiology of depression and the mechanism of action of antidepressants. ${ }^{5}$ These data suggest that the inhibitory effect of fluoxetine is exerted directly on NMDA receptors, contributing to the therapeutic effects of these drugs. ${ }^{6,7}$ However, the evidence for the effect of fluoxetine on animal models of anxiety is controversial. Some studies report an anxiolytic-like, an anxiogenic-like, or no effect in various anxiety-like tests. ${ }^{8-10}$ The methodological diversity of these studies makes it difficult to establish which other variables (from genetic differences to features of the task used in the study) interact with fluoxetine to produce this wide range of results.

The limitations of current antidepressant drugs have warranted ongoing research to identify pharmacological agents and strategies that offer greater therapeutic efficacy. Depression and anxiety play an important role in decreasing quality of life worldwide. Preclinical data have demonstrated that blocking the NMDA receptor complex produced anxiolytic and antidepressant activity in animal tests. ${ }^{11-13}$ Thus, simvastatin combined with fluoxetine provide a potential mechanism for the anxiolytic and antidepressant properties of drugs in animal models. The current study was designed to systematically assess the effects of simvastatin combined with fluoxetine and involved the elevated plusmaze, a model of anxiety, and the forced swimming test, a model of depression. An open-field test was used as an independent measure of general activity.

\section{Materials and methods Subjects}

A total of 72 genetically heterogeneous male Wistar albino rats (Rattus norvegicus), 3 to 5 months of age, weighing 220 to $310 \mathrm{~g}$, were obtained from the animal house of the Regional University of Blumenau. After arrival in the sectorial animal house of the laboratory, these animals were housed in groups of five per opaque plastic cage $(50 \times 30 \times 15 \mathrm{~cm})$. Cages had wood shaving bedding and wire mesh tops and were under a standard light cycle (12-hour light/dark phase) in a temperature-controlled environment $\left(23^{\circ} \mathrm{C} \pm 1{ }^{\circ} \mathrm{C}\right)$ with a relative humidity of $55 \% \pm 10 \%$. During the light and dark phases, the rats were exposed to a light intensity of approximately 500 and 0.025 lux, respectively. These lux values were chosen because they were the closest values (in our laboratory) possible to natural daytime and nighttime light. During the entire experimental period, the animals received commercial chow for rodents $\left(\right.$ Nuvital $^{\circledR}$, Paraná, Brazil) and filtered tap water ad libitum. The room was entered at irregular intervals on an average of once every 2 or 3 days for the purposes of cleaning cages and placing food and water. Animals were acclimatized to the animal housing facilities for at least 1 week before starting the experiments. The experiments reported in this article were performed in compliance with the recommendations of Brazilian Society of Neuroscience and Behavior ( $\mathrm{SBNeC}$ ), which are based on the US National Institutes of Health Guide for Care and Use of Laboratory Animals.

\section{Experimental protocols}

Drug treatments in the behavioral tests were administered with a subchronic exposure and subacute intraperitoneal exposure pattern. The rats were orally administered simvastatin (1 or $10 \mathrm{mg} / \mathrm{kg}$ by oral gavage, once daily; Zocor ${ }^{\mathbb{B}}$; Merck KGaA, Darmstadt, Germany) for 30 days. Groups were randomized with eight rats per group and intraperitoneally administered with fluoxetine ( 2 or $10 \mathrm{mg} / \mathrm{kg}$; Psiquial $^{\circledR}$; Merck) at 24,5 , and 1 hour(s) before the behavioral tests. The dose of fluoxetine used in the subacute schedule is in the same schedule and range of the doses that reduced the time spent in immobility in forced swimming test. ${ }^{14}$ Control rats received saline.

\section{Behavioral tests}

The animals were subjected individually to the elevated plus-maze, open-field, and forced swim tests. All behavioral procedures were conducted during the light phase (between 8 and 12 hours), when rodents are less active, in a soundisolated room. To minimize possible circadian influences on the rats, experimental and control observations were alternated. The observer remained in the same room at least $1 \mathrm{~m}$ away from the elevated plus-maze, open-field, and forced swim tests. ${ }^{15-17}$

\section{Elevated plus-maze test}

The apparatus consisted of two open arms $(50 \times 10 \mathrm{~cm})$ and two enclosed arms $(50 \times 10 \times 40 \mathrm{~cm})$, arranged in such a way that the two arms of each type were opposite to each other, and a central platform $(10 \times 10 \mathrm{~cm})$. The maze's height was $50 \mathrm{~cm}$ and the tests were conducted under dim red light (44 lux). Animals were exposed to the red light for 5 minutes in their own home cages before the testing procedure. Next, they 
were placed individually on the central platform of the plusmaze facing an open arm. During a 5-minute test period, the following measurements were recorded by the observer: time spent on the open arms, number of entries in the open arms, time spent on the closed arms, number of entries in the enclosed arms, and risk assessment. Risk assessment is a measure that accounts for time spent in the head-dipping (exploratory movement of head/shoulders over the side of the maze), and stretched attend (exploratory posture in which the body is stretched forward then retracted to the original position without any forward locomotion) postures. The measures that reflect anxiety-like levels in this test are the percentage of entries into open arms versus closed arms and the percentage of time spent in the open arms versus closed arms. We also included ethologically derived measures related to the defensive pattern of risk assessment behavior, which has been shown to be very sensitive to changes in anxiety. ${ }^{15}$

\section{Open-field test}

The open field consisted of a black circular box $(60 \mathrm{~cm}$ in diameter and $50 \mathrm{~cm}$ high). Each rat was placed in the central area and allowed to explore freely for 5 minutes. The tests were conducted under dim red light (44 lux). The following parameters were recorded: time spent ambulating in the central and peripheral areas; time for which the animal did not move at all (freezing); time rearing (rising on the hind paws); and time the animal performed self-cleaning (grooming). The total time spent in ambulation and freezing was determined as a measure of activity. Exploration behavior in the openfield has also been used as a measure of defensive behavior, where increased line-rearing responses are suggestive of a decrease in defensive behaviors. ${ }^{16}$

\section{Forced swimming test}

The procedure used was previously described by Detke et al. ${ }^{17}$ The animals were forced to swim inside a cylinder filled with water without the possibility of escaping. The resulting anxiety produces vigorous swimming activity and attempts at escaping by diving or climbing the walls of the cylinder. When the animals ceased all movements except those necessary for survival (keeping the head above the water), the behavior was considered to be immobile. This was classified as induced depression. On the first day (pre-session test), the rats were forced to swim for 15 minutes in an acrylic cylinder $(29 \mathrm{~cm}$ diameter $\times 50 \mathrm{~cm}$ tall) containing $25^{\circ} \mathrm{C}$ water $40 \mathrm{~cm}$ deep. The water was changed after every swimming test to eliminate urine, excrement, and fur. After the swimming session, the rats were removed from the cylinder, dried with towels, and placed under a light bulb $\left(32^{\circ} \mathrm{C}\right)$ for $15-30$ minutes. They then received the first dose of their respective drugs and were returned to their home cages. Twenty-four hours later, the rats were tested under the same conditions for 5 minutes (test session). They received the second and third doses of their respective drugs 5 and 1 hour(s) prior to the test session. Immobility and the number of times the rats stopped swimming (number of stops) were measured. Immobility referred to the absence of movement, with the body inclined forward, passively floating, and the paws immobile. Swimming was coded when large forepaw movements displacing the body around the cylinder more than necessary to merely keep the head above the water were performed. Climbing was recorded when the rat began vigorous movements with forepaws in and out of the water, typically directed against the wall of the tank.

\section{Statistical analysis}

The data were reported as the mean \pm standard error of the mean (SEM) and were analyzed statistically using analysis of variance (ANOVA) followed by the Newman-Keuls post hoc test. Differences were considered to be significant when $P<0.05$.

\section{Results}

Analysis of variance revealed significant differences between groups on the percent time spent by rats in the open arms of the elevated plus-maze $(\mathrm{F}=4.979 ; P<0,001$; Figure 1A). The experimental groups orally administered with either $10 \mathrm{mg} / \mathrm{kg} /$ day of simvastatin combined with $10 \mathrm{mg} / \mathrm{kg}$ of fluoxetine demonstrated increased time spent in the open arms on the day of experiment when compared with the other groups $(P<0.01)$. In addition, $10 \mathrm{mg} / \mathrm{kg}$ / day of simvastatin combined with saline or fluoxetine ( 2 or $10 \mathrm{mg} / \mathrm{kg}$ ) decreased the percent time spent in enclosed arm $(\mathrm{F}=7.556 ; P<0.001, P<0.01$, and $P<0.05$, respectively; Figure 1B). There was no significant difference in groups in the percent frequency of open arm entries $(\mathrm{F}=2.207 ; P=0.0489$; Figure $1 \mathrm{C})$ and percent frequency of enclosed arm entries ( $\mathrm{F}=2.126 ; P=0.0494$; Figure 1D). In case of percent risk assessment time, there were significant differences between groups $(\mathrm{F}=11.170 ; P<0.001$; Figure 1E). The rats administered with either 1 or $10 \mathrm{mg} /$ $\mathrm{kg} /$ day of simvastatin combined with saline $(P<0.01$ and $P<0.001$, respectively) or $2 \mathrm{mg} / \mathrm{kg}$ of fluoxetine $(P<0.05$ and $P<0.01$, respectively) and $10 \mathrm{mg} / \mathrm{kg}$ of fluoxetine $(P<0.001)$ showed increased risk assessment time compared to saline treatment. 
A
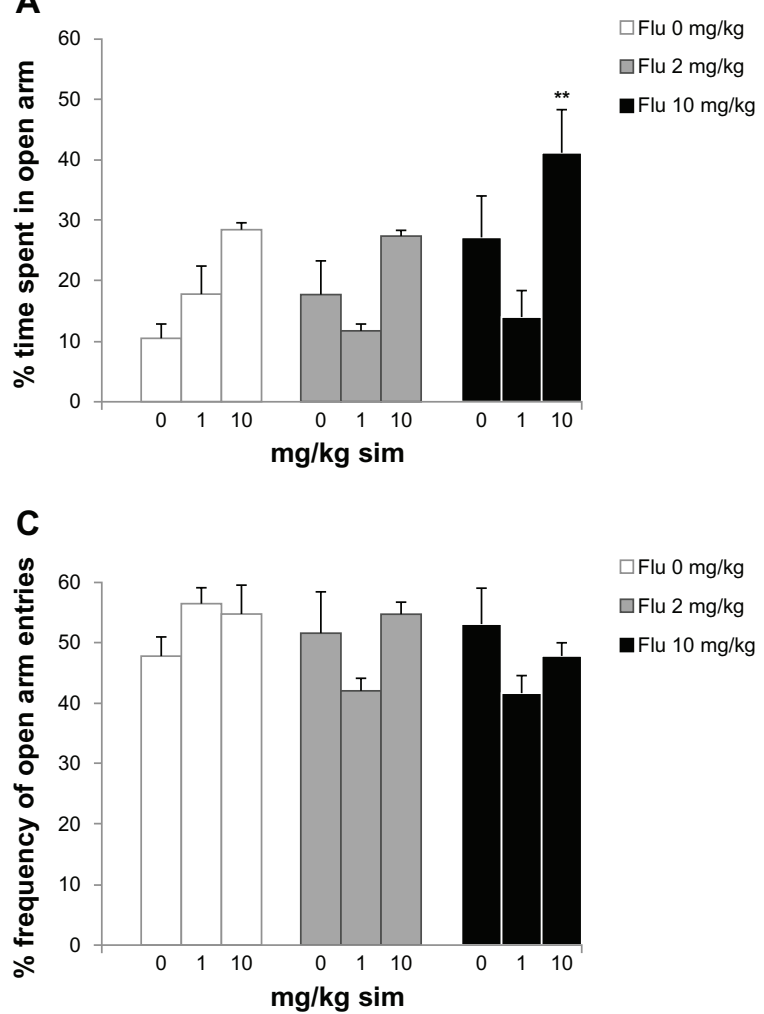

B

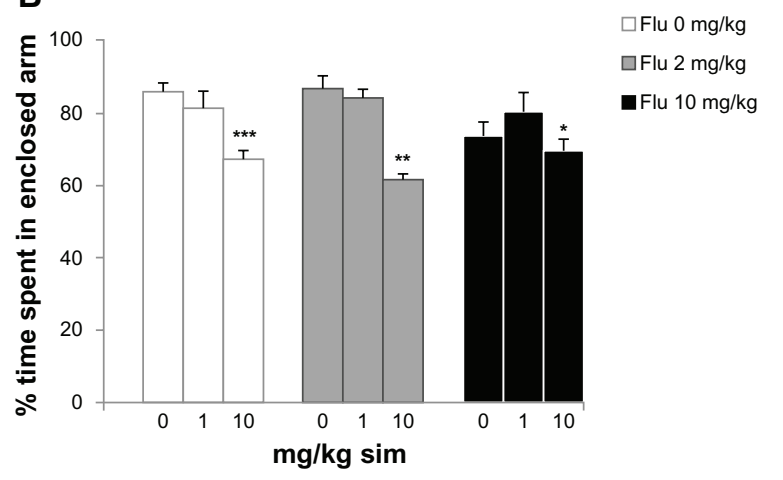

D

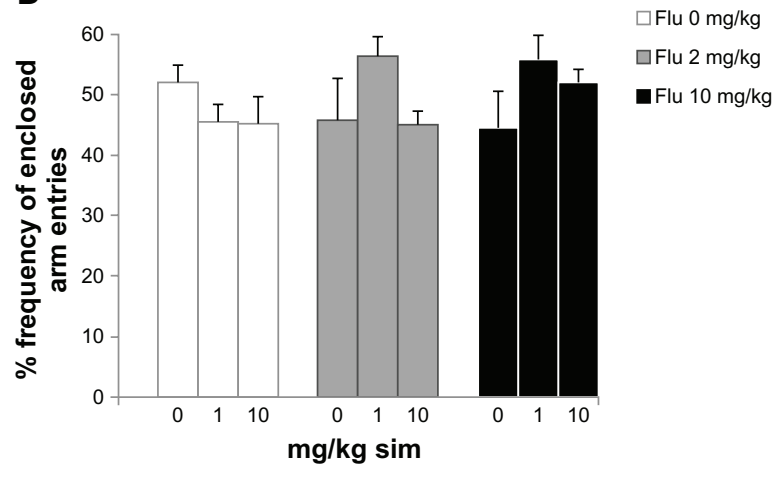

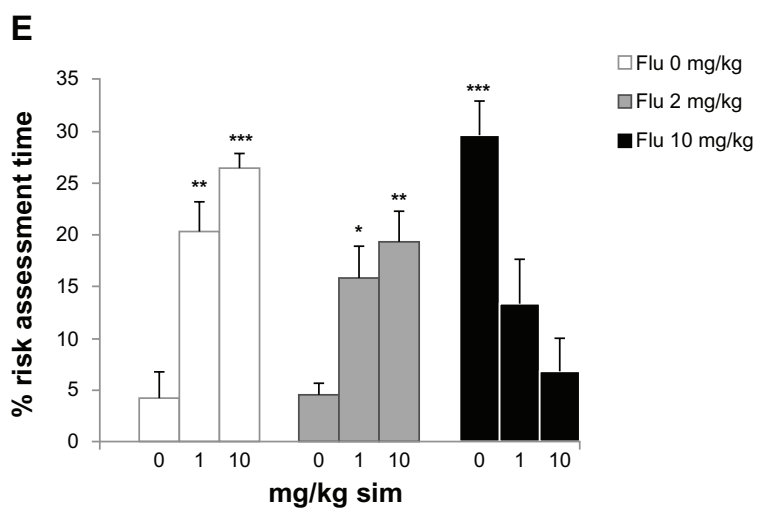

Figure I Behavioral responses in the elevated plus-maze of subchronic simvastatin treatment combined with fluoxetine (Flu) in rats: (A) percent time spent in open arm; (B) percent time spent in enclosed arm; (C) percent frequency of open arm entries; (D) percent frequency of enclosed arm entries; and (E) percent risk assessment time. Notes: Bars represent the means for each group and the vertical lines represent the standard errors of the means. Newman-Keuls test showed that groups with asterisks are significantly different $(n=8 ; * P<0.05 ; * * P<0.01$; ***P $<0.001)$.

ANOVA revealed significant differences between groups for percent ambulation/interior zone time of the open-field test $(\mathrm{F}=8.387 ; P<0.001$; Figure $2 \mathrm{~A})$. The experimental group orally administered $10 \mathrm{mg} / \mathrm{kg}$ /day of simvastatin combined with $10 \mathrm{mg} / \mathrm{kg}$ of fluoxetine showed increased ambulation/interior zone time when compared with the other groups $(P<0.001)$. There was no significant difference in groups in the percent ambulation/outside zone time ( $\mathrm{F}=2.186 ; P=0.0498$, Figure $2 \mathrm{~B})$. In addition, the rats administered either $10 \mathrm{mg} / \mathrm{kg} /$ day of simvastatin combined with $10 \mathrm{mg} / \mathrm{kg}$ of fluoxetine showed decreased immobility percent time $(\mathrm{F}=6.324 ; P<0.001$; Figure $2 \mathrm{C})$. ANOVA revealed significant differences between groups in the percent time spent rearing $(\mathrm{F}=6.698 ; P<0.001$; Figure 2D). The rats administered either $1 \mathrm{mg} / \mathrm{kg} /$ day of simvastatin increased the time spent rearing when compared with the other groups $(P<0.01)$. There was no significant difference between groups for percent time spent grooming $(\mathrm{F}=1.355$; $P=0.0491$; Figure 2D).

ANOVA revealed significant differences between groups for percent immobility time in the forced swimming test $(\mathrm{F}=14.026 ; P<0.001 ;$ Figure $3 \mathrm{~A})$. The experimental groups 
A

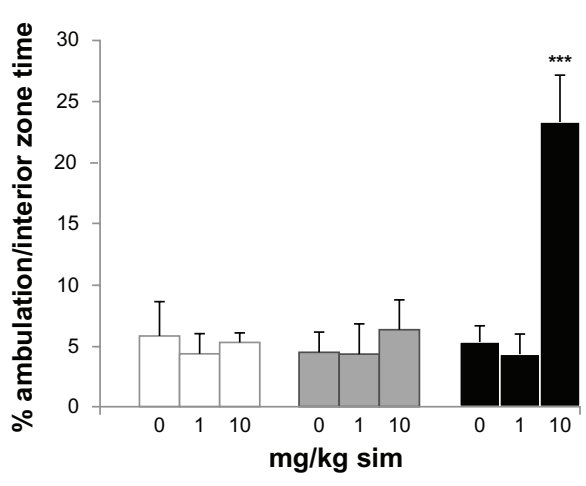

C

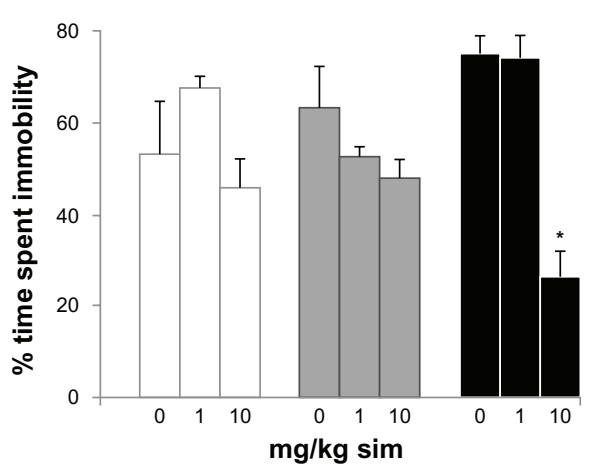

B

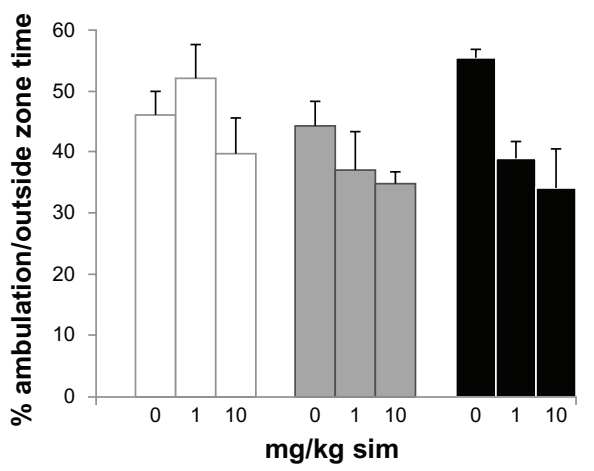

$\square$ Flu $0 \mathrm{mg} / \mathrm{kg}$

口Flu $2 \mathrm{mg} / \mathrm{kg}$

Flu $10 \mathrm{mg} / \mathrm{kg}$
D

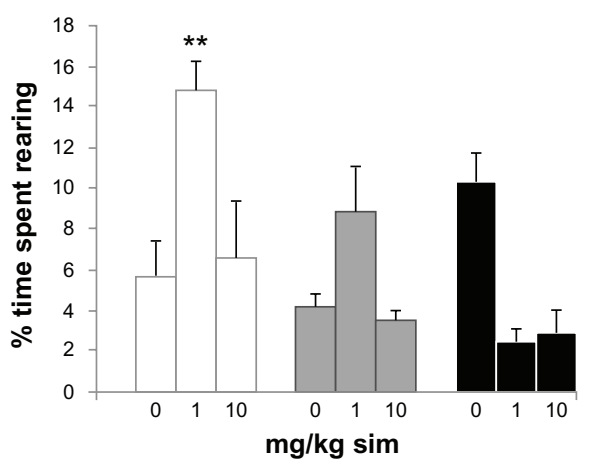

$\square$ Flu $0 \mathrm{mg} / \mathrm{kg}$ 口Flu $2 \mathrm{mg} / \mathrm{kg}$ EFlu $10 \mathrm{mg} / \mathrm{kg}$

E

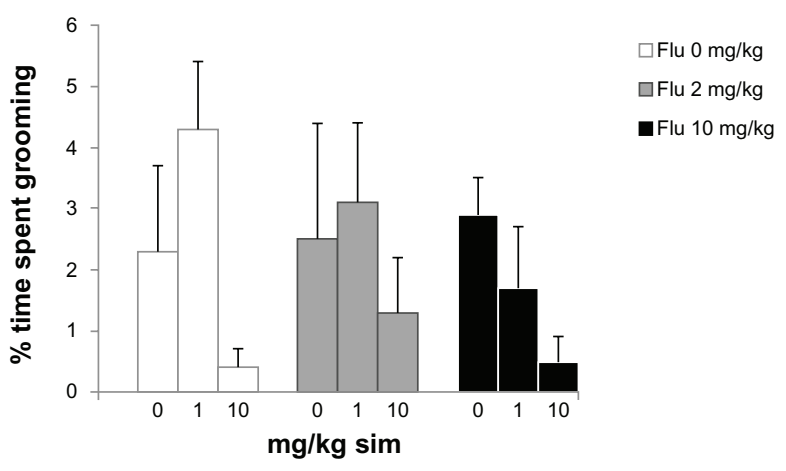

Figure 2 Behavioral responses in the open field of subchronic simvastatin (sim) treatment combined with fluoxetine (Flu) in rats: (A) percent ambulation/interior zone time; (B) percent ambulation/outside zone time; (C) percent time spent immobile; (D) percent time spent rearing; and (E) percent time spent grooming.

Notes: Bars represent the means for each group and the vertical lines represent the standard errors of the means. Newman-Keuls test showed that groups with asterisks are significantly different $(\mathrm{n}=8 ; * \mathrm{P}<0.05 ; * * \mathrm{P}<0.01$; *** $\mathrm{P}<0.001)$.

orally administered either $1 \mathrm{mg} / \mathrm{kg} /$ day of simvastatin, $2 \mathrm{mg} / \mathrm{kg}$ of fluoxetine, $1 \mathrm{mg} / \mathrm{kg} /$ day of simvastatin combined with $2 \mathrm{mg} / \mathrm{kg}$ of fluoxetine, and 1 or $10 \mathrm{mg} / \mathrm{kg} /$ day of simvastatin combined with $10 \mathrm{mg} / \mathrm{kg}$ of fluoxetine showed decreased percent immobility time on the day of experiment when compared to saline treatment $(P<0.001)$. In addition, the rats administered 1 or $10 \mathrm{mg} / \mathrm{kg} /$ day of $\operatorname{simvastatin}(P<0.001$ and $P<0.01$, respectively), 1 or $10 \mathrm{mg} / \mathrm{kg} /$ day of simvastatin combined with $2 \mathrm{mg} / \mathrm{kg}$ of fluoxetine $(P<0.001$ and $P<0.01$, respectively), and 1 or $10 \mathrm{mg} / \mathrm{kg} /$ day of simvastatin combined with $10 \mathrm{mg} / \mathrm{kg}$ of fluoxetine $(P<0.001)$ showed decreased number of stops $(\mathrm{F}=10.441 ; P<0.001$; Figure $3 \mathrm{~B})$. For percent swimming time, there were significant differences between groups $(\mathrm{F}=69.605 ; P<0.001$; Figure $3 \mathrm{C})$. The rats administered $1 \mathrm{mg} / \mathrm{kg} /$ day of simvastatin, $2 \mathrm{mg} / \mathrm{kg}$ of fluoxetine, and $1 \mathrm{mg} / \mathrm{kg} /$ day of simvastatin combined with 2 or $10 \mathrm{mg} / \mathrm{kg}$ of fluoxetine increased the swimming time $(P<0.001)$. In addition, the rats administered $10 \mathrm{mg} / \mathrm{kg} /$ day of simvastatin combined with saline and 2 or $10 \mathrm{mg} / \mathrm{kg}$ of fluoxetine showed decreased swimming time ( $P<0.05 ; P<0.01$ and $P<0.01$; respectively). For percent climbing time, there were significant differences 
A

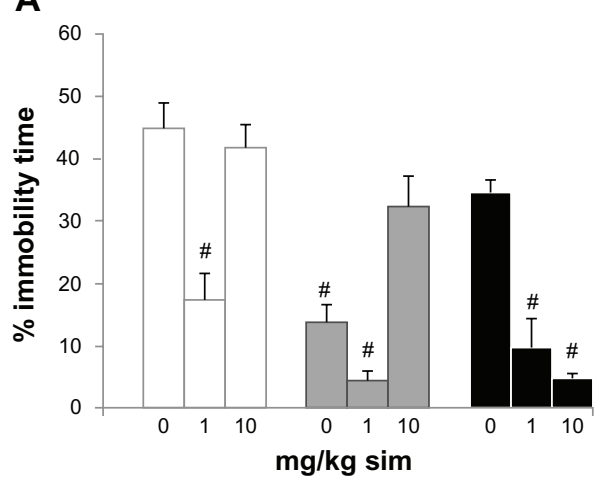

C

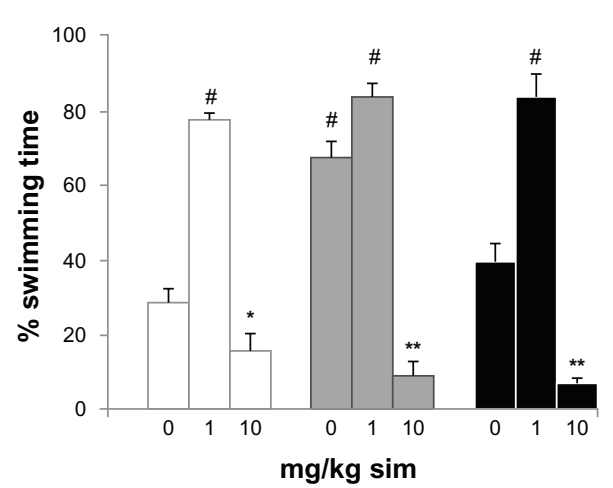

$\square$ Flu 0 mg/kg 口Flu 2 mg/kg

EFlu 10 mg/kg
B

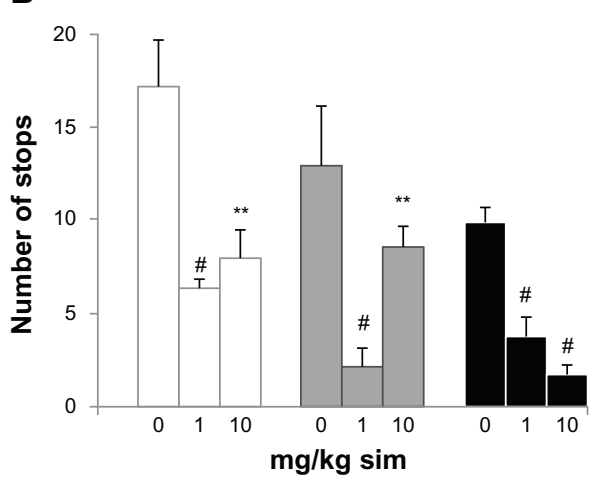

$\square$ Flu 0 mg/kg 다u $2 \mathrm{mg} / \mathrm{kg}$

-Flu 10 mg/kg

Figure 3 Behavioral responses in the forced swimming test of sub-chronic simvastatin (sim) treatment combined with fluoxetine (Flu) in rats: (A) percent immobility time; (B) number of stops; (C) percent swimming time; and (D) percent climbing time.

Notes: Bars represent the means for each group and the vertical lines represent the standard errors of the means. Newman-Keuls test showed that groups with asterisks are significantly different $(n=8 ; * P<0.05 ; * * P<0.01 ; * P<0.001)$.

between groups ( $\mathrm{F}=16.065 ; P<0.001$; Figure 3D). The rats administered with $10 \mathrm{mg} / \mathrm{kg} /$ day of simvastatin combined with saline and 2 or $10 \mathrm{mg} / \mathrm{kg}$ of fluoxetine increased the climbing time $(P<0.001)$. Coadministration of $10 \mathrm{mg} / \mathrm{kg} /$ day of simvastatin with $10 \mathrm{mg} / \mathrm{kg}$ of fluoxetine is significantly different from other groups.

\section{Discussion}

The results of our experiments suggest that exposure to subchronic treatment with simvastatin reduced anxiety levels in rats when administered with fluoxetine. The experimental groups orally administered $10 \mathrm{mg} / \mathrm{kg} /$ day of simvastatin combined with $10 \mathrm{mg} / \mathrm{kg}$ of fluoxetine showed increased time spent in the open arms on the day of experiment when compared with the other groups (Figure 1A). The elevated plus-maze is a widely used animal model of anxiety that is based on two conflicting tendencies, including the rodent's drive to explore a novel environment and its aversion to open spaces. Thus, anxious animals will spend the most time in the closed arms, while less anxious animals will explore open areas for a longer period of time. ${ }^{15} \mathrm{In}$ addition, $10 \mathrm{mg} / \mathrm{kg} /$ day of simvastatin combined with saline or fluoxetine decreased the time spent in the enclosed arm (Figure 1B). These effects were observed in the absence of significant changes in general locomotive activity, represented by enclosed arm entries (Figure 1D). Our results show that, in male rats, subchronic simvastatin administration, subacute fluoxetine administration, or simvastatin combined with fluoxetine increased risk assessment time compared to the effect of saline treatment (Figure 1E). These ethological elements, which include stretched attend postures and head-dipping, have been linked through factor analysis to risk assessment, directed exploration, and displacement activity. ${ }^{18}$ Furthermore, pharmacological studies have shown that the incorporation of such measures in plus-maze scoring not only reduces the likelihood of false positives and negatives, ${ }^{19}$ but also enhances the sensitivity of the model to novel anxiolytic. ${ }^{20}$ These results strongly indicate that simvastatin and/or fluoxetine treatment results in improved coping with aversive situations, thus leading to a reduced anxiety level and playing an important role in the synergistic effect of combination therapy. These findings indicate that 
simvastatin or fluoxetine did not increase the time spent in the open arms in the elevated plus-maze, but their effects may be increased when they are used combined at a high dose. This synergistic effect was not observed, however, for coadministration of simvastatin and fluoxetine based on risk assessment.

The differences in anxiotypic behavior expressed by these animals are not limited to their performance on the elevated plus-maze. The novel environment is an established measure of general anxiotypic behavior, and levels of locomotion and rearing in this paradigm can be used as indices of an anxietylike state in rats. ${ }^{17}$ The experimental group orally administered with either $10 \mathrm{mg} / \mathrm{kg} /$ day of simvastatin combined with $10 \mathrm{mg} / \mathrm{kg}$ of fluoxetine increased ambulation/interior zone time in the open-field (Figure 2A). Locomotion can be assessed by time spent in each of the two zones (central and peripheral) and can be used in addition to the classical test as an indicator of anxiety. ${ }^{21}$ Traveling close to the wall is an important feature of the rats, and it has been suggested that the wall confers security while the center is anxiogenic. ${ }^{22}$ Thus, the increase the time spent in the ambulation/interior zone indicates an anxiolytic-like effect in the experimental group receiving simvastatin combined with of fluoxetine. In addition, the rats administrated with either $10 \mathrm{mg} / \mathrm{kg}$ /day of simvastatin combined with $10 \mathrm{mg} / \mathrm{kg}$ of fluoxetine decreased time spent in an immobile state (Figure 2C). The decreased immobility in the open-field is characteristic of decreased levels of anxiety. ${ }^{23}$ Our results show that the $1 \mathrm{mg} / \mathrm{kg}$ /day of simvastatin increased the time spent rearing in open field (Figure 2D). In this context, it has also been proposed that changes observed in the time spent in rearing somewhat reflect changes in the level of locomotor activity. ${ }^{22}$ It is probable that both are indices of rearing behavior and both depend on the level of anxiety and level of locomotor activity. ${ }^{22}$ These results indicate that simvastatin and/or fluoxetine treatment reduces anxiety-like behaviors in two animal tests of anxiety without significantly changing total activity levels, indicating a synergistic effect of combination drug administration. Additionally, co-treatment with simvastatin and fluoxetine increased ambulation/ interior zone time in the open-field. Our results indicate that the NMDA receptor antagonists simvastatin and fluoxetine provide a potential mechanism for the anxiolytic properties of drugs in animal models.

Our results indicate the effects of simvastatin treatment on NMDA receptor binding density in the brain and reveal a possible NMDA antagonist-like effect, providing an exciting and potential paradigm to ameliorate anxiety deficits. ${ }^{3}$ This study showed that compared with the saline group, treatment of male Sprague-Dawley rats with simvastatin at a high dose $(10 \mathrm{mg} / \mathrm{kg} /$ day $)$ produced a significantly longer traveled distance and higher average velocity in an open-field arena, suggesting hyperlocomotive activity, while increased time traveled in the open arms in an elevated plus-maze was also observed, reflecting reduced anxiety-like behavior. ${ }^{3}$ However, our studies showed contrasting results for treatment of male Wister rats with simvastatin. Different rat strains as well as differing test conditions have a major impact on the outcome of this animal test for anxiety. ${ }^{24}$ However, our results suggest that exposure to sub-chronic treatment with simvastatin reduces anxiety levels in male Wistar rats when associated with fluoxetine treatment. The present study is the first to show that simvastatin combined with fluoxetine has anxiolyticlike effects in the elevated plus-maze and hyperlocomotive activity in the open-field test. A possible mechanism mediating these effects may involve modulation of NMDA receptors. ${ }^{3,7}$ These results indicate that fluoxetine can serve as an effective adjuvant in rats treated with simvastatin, and that this species may be used in other preclinical models utilizing drug interventions.

In the forced swimming test, groups orally administered with simvastatin, fluoxetine, and simvastatin combined with fluoxetine decreased the immobility time (Figure 3A). This potentiation manifested as a reduction of the immobility time in the forced swimming test without an influence on locomotor activity. ${ }^{25}$ Typically, the open-field test is employed along with the forced swimming test in order to control for the effects of drugs on locomotion. ${ }^{16}$ In this case, only the rats administered $10 \mathrm{mg} / \mathrm{kg} /$ day of simvastatin combined with $10 \mathrm{mg} / \mathrm{kg}$ of fluoxetine showed decreased time spent immobile. In the open-field test, the antidepressant compounds did not alter or reduce locomotor activity, verifying their selective effects during the forced swimming test. ${ }^{16}$ Stimulant drugs, such as amphetamine or cocaine, can decrease immobility in the forced swimming test. $^{26}$ This is a false positive result and is distinguished from the antidepressant-like reduction in immobility by assessing locomotor activity in the open-field test. In addition, rats given drug treatment displayed significantly less immobility and stops than the control rats. The simvastatin and simvastatin combined with fluoxetine decreased the number of stops (Figure 3B). The immobilization represents a state of desperation in the rodents, which is a symptom of depression. Porsolt et $\mathrm{al}^{27}$ found that such immobility is reflective of a low-mood state in the rats, which is sensitive to antidepressant treatment. However, rats given antidepressant 
drug treatment displayed significantly less immobility and stops than the control rats.

A marked increase in the swimming activity of rats was observed. The groups orally administered with either simvastatin, fluoxetine, and simvastatin combined with fluoxetine increased the swimming time (Figure 3C). Interestingly, fluoxetine generally produced no effect on climbing time (Figure 3D). Some authors observed antidepressant-like activity, while others did not. ${ }^{28} \mathrm{~A}$ possible reason may be the use of different rat strains. ${ }^{29}$ Further behavioral registration of the time spent swimming in the tank or climbing (attempted vertical movement) allows the detection of the selective serotonin reuptake inhibitors and the discrimination between drugs primarily affecting the serotonergic or noradrenergic neurotransmitter systems. ${ }^{29-31}$ While drugs stimulating the serotonergic system, such as selective serotonin reuptake inhibitors, preferentially stimulate active swimming in the water tank, drugs primarily blocking noradrenaline uptake preferentially increase climbing behavior. The selective serotonin reuptake inhibitor fluoxetine boosted swimming behavior. Because the effects of simvastatin on the measured parameters in the forced swimming test are different to those of fluoxetine (reduced immobility, enhanced climbing), it is conceivable that the action of simvastatin may involve the noradrenergic system. However, the effect of simvastatin is potentiated by fluoxetine. Evidence regarding the effect of statins combined with fluoxetine on animal models of depression is controversial. Specifically, supplementation with lovastatin increases the antidepressant efficacy of fluoxetine in laboratory animals, as shown by reduced immobility and increased swimming in rats, ${ }^{32}$ and the action of lovastatin may involve the serotonergic (rather than noradrenergic) pathways, supporting the proposal that statins increase serotonergic function.

The monoamine theory of depression has predominated with regards to the etiology of the illness itself as well as the rationale behind most treatments available in the clinic. Currently, some of the most widely prescribed antidepressant drugs are those which have high degrees of selectivity for the 5-hydroxytryptamine transporter, the selective serotonin reuptake inhibitors (eg, fluoxetine) and, to a lesser extent, those with a high degree of selectivity for the noradrenaline transporter, the selective noradrenaline reuptake inhibitors (eg, reboxetine). ${ }^{33}$ In addition, studies suggest that the NMDA antagonists did not potentiate the antidepressant-like effects of noradrenergic antidepressants. ${ }^{34}$ However, simvastatin or fluoxetine induces an adaptive change to the binding properties of the NMDA receptor, ${ }^{4-7}$ and we hypothesized that noradrenergic function would be critical for the action of simvastatin combined with fluxoetine. The neurobiological mechanisms by which antidepressants achieve alterations in the radioligand-binding characteristics of the NMDA receptor are unclear. Multiple lines of evidence have demonstrated that norepinephrine can modulate glutamatergic neurotransmission. ${ }^{35}$ Thus, antidepressantinduced adaptations to the NMDA receptor complex may be secondary to antidepressant action at monoaminergic terminals. These findings suggest that neurochemical effects beyond alterations in noradrenergic transmission may be mechanistically significant in antidepressant drug action.

Other possible mechanisms include the modulation of cholesterol distribution within brain cell membranes. ${ }^{36}$ Due to the relatively high concentration of cholesterol in the brain, the detection of changes specific to membrane cholesterol is difficult. However, several lines of evidence have demonstrated that chronic administration of simvastatin does not change the cholesterol level in brain tissue and plasma of rodents. ${ }^{3,37-39}$ It is reasonable to hypothesize that the simvastatin effects on the central nervous system occur via a central mechanism independent of hypocholesterolemic properties. Interestingly, in human studies, simvastatin lowered plasma cholesterol. ${ }^{40}$ The contradictory findings may result from the different cholesterol metabolisms in humans and rodents. This suggests that genes directly involved in cholesterol synthesis in rodents are relatively unaffected by statin treatment. ${ }^{41}$

Several important clinical implications emerge with the finding that simvastatin is associated with the behavioral effects of fluoxetine in the forced swimming test. First, the forced swimming test is one of the best animal behavior tests at predicting the clinical activity of antidepressants. ${ }^{16}$ The forced swimming test appears to model "behavioral despair," ${ }^{27}$ passive coping strategies in response to stress, or entrapment through uncontrollable exposure to severe stress in rodents, ${ }^{28,29}$ and similar behavioral processes are thought to be part of clinical depression. Second, antidepressant-like behavioral effects of simvastatin and fluoxetine indicate that the neural circuitry associated with these effects may be similar. The conceptual hypothesis that antidepressants produce their behavioral effects through different mechanisms provides important direction for future clinical research. For example, the results suggest that, like other NMDA antagonists, simvastatin combined 
with fluoxetine possesses antidepressant-like actions in preclinical tests predictive of clinical efficacy, and this is of particular relevance for antidepressant-resistant patients who develop hypocholesterolemia. Recently, significant attention has been devoted to the glutamatergic system and to NMDA receptor antagonists. ${ }^{42-44}$ It is information may be important for continuing to define distinguishable preclinical and clinical behavioral effects for different types of antidepressant drugs. It may suggest that research efforts should be shifted to the pursuit of new glutamatergic (or other alternative) avenues, rather than examining monoaminergic drug development if we hope to identify truly novel drugs with unique and improved therapeutic profiles.

\section{Conclusion}

The results described in the present paper indicate that coadministration of simvastatin with fluoxetine induces a more pronounced anxiolytic activity than treatment with drugs alone in elevated plus-maze and open-field tests. In addition, the present findings suggest the antidepressant efficacy of simvastatin combined with fluoxetine. Our behavioral sampling data suggest preferential effects of simvastatin on the noradrenergic system, but additional work (eg, in vivo microdialysis) is needed to examine the effects of statins on brain catecholamines. Regardless, this is the first report of the ability of a fluoxetine drug to potentiate key behavioral effects of a statin. Some of these issues can be addressed in experimental animal models, which allow for the control and manipulation of many of these variables.

\section{Disclosure}

The authors report no conflicts of interest in this work.

\section{References}

1. Sett AK, Robinson TG, Mistri AK. Current status of statin therapy for stroke prevention. Expert Rev Cardiovasc Ther. 2011;9(10): 1305-1314.

2. Swindle JP, Potash J, Kulakodlu M, Kuznik A, Buikema A. Drug utilization patterns and cardiovascular outcomes in elderly patients newly initiated on atorvastatin or simvastatin. Am J Geriatr Pharmacother. 2011;9(6):471-482.

3. Wang Q, Zengin A, Deng C, et al. High dose of simvastatin induces hyperlocomotive and anxiolytic-like activities: The association with the up-regulation of NMDA receptor binding in the rat brain. Exp Neurol. 2009;216(1):132-138.

4. Zhang X, Tao Y, Troiani L, Markovic-Plese S. Simvastatin inhibits IFN regulatory factor 4 expression and Th17 cell differentiation in CD4+ $\mathrm{T}$ cells derived from patients with multiple sclerosis. J Immunol. 2011; 187(6):3431-3437.

5. Szasz BK, Mike A, Karoly R, et al. Direct inhibitory effect of fluoxetine on N-methyl-D-aspartate receptors in the central nervous system. Biol Psychiatry. 2007;62(11):1303-1309.
6. Bolo NR, Hodé Y, Nédélec JF, Lainé E, Wagner G, Macher JP. Brain pharmacokinetics and tissue distribution in vivo of fluvoxamine and fluoxetine by fluorine magnetic resonance spectroscopy. Neuropsychopharmacology. 2000;23(4):428-438.

7. Mayer A, Szasz BK, Kiss JP. Inhibitory effect of antidepressants on the NMDA-evoked [(3)H]noradrenaline release from rat hippocampal slices. Neurochem Int. 2009;55(6):383-388.

8. Durcan MJ, Lister RG, Eckardt MJ, Linnoila M. Behavioral interactions of fluoxetine and other 5-hydroxytryptamine uptake inhibitors with ethanol in tests of anxiety, locomotion and exploration. Psychopharmacology (Berl). 1988;96(4):528-533.

9. Robert G, Drapier D, Bentué-Ferrer D, Renault A, Reymann JM. Acute and chronic anxiogenic-like response to fluoxetine in rats in the elevated plus-maze: modulation by stressful handling. Behav Brain Res. 2011;220(2):344-348.

10. Rogóz Z, Skuza G. Anxiolytic-like effects of olanzapine, risperidone and fluoxetine in the elevated plus-maze test in rats. Pharmacol Rep. 2011;63(1):1547-1552.

11. Pittenger C, Sanacora G, Krystal JH. The NMDA receptor as a therapeutic target in major depressive disorder. CNS Neurol Disord Drug Targets. 2007;6(2):101-115.

12. Riaza Bermudo-Soriano C, Perez-Rodriguez MM, Vaquero-Lorenzo C, Baca-Garcia E. New perspectives in glutamate and anxiety. Pharmacol Biochem Behav. 2012;100(4):752-774.

13. Skolnick P, Popik P, Trullas R. Glutamate-based antidepressants 20 years on. Trends Pharmacol Sci. 2009;30(11):563-569.

14. Rogóz Z, Skuza G, Maj J, Danysz W. Synergistic effect of uncompetitive NMDA receptor antagonists and antidepressant drugs in the forced swimming test in rats. Neuropharmacology. 2002;42(1): 1024-1030.

15. Pellow S, Chopin P, File SE, Briley M. Validation of open: closed arm entries in the elevated plus-maze as a measure of anxiety in the rat. J Neurosci Methods. 1985;14(3):149-167.

16. Prut L, Belzung $\mathrm{C}$. The open field as a paradigm to measure the effects of drugs on anxiety-like behaviors: a review. Eur J Pharmacol. 2003; 463(1-3):3-33.

17. Detke MJ, Rickels M, Lucki I. Active behaviors in the rat forced swimming test differentially produced by serotonergic and noradrenergic antidepressants. Psychopharmacology (Berl). 1995;121(1): 66-72.

18. Cruz AP, Frei F, Graeff FG. Ethopharmacological analysis of rat behavior on the elevated plus-maze. Pharmacol Biochem Behav. 1994;49(1):171-176.

19. Rodgers RJ, Cole JC. An ethological analysis of chlordiazepoxide and bretazenil (Ro 16-6028) in the murine elevated plus-maze. Behav Pharmacol. 1993;4(6):573-580.

20. Setem J, Pinheiro AP, Motta VA, Morato S, CruzAP. Ethopharmacological analysis of 5-HT ligands on the rat elevated plus-maze. Pharmacol Biochem Behav. 1999;62(3):515-521.

21. Kalueff AV, Wheaton M, Murphy DL. What's wrong with my mouse model? Advances and strategies in animal modeling of anxiety and depression. Behav Brain Res. 2007;179(1):1-18.

22. Lister RG. Ethologically-based animal models of anxiety disorders. Pharmacol Ther. 1990;46(3):321-340.

23. Kalueff AV, Tuohimaa P. Grooming analysis algorithm for neurobehavioural stress research. Brain Res Brain Res Protoc. 2004; 13(3):151-158.

24. Rex A, Voigt JP, Gustedt C, Beckett S, Fink H. Anxiolytic-like profile in Wistar, but not Sprague-Dawley rats in the social interaction test. Psychopharmacol (Berl). 2004;177(1-2):23-34.

25. Poleszak E, Wlaź P, Szewczyk B, et al. A complex interaction between glycine/NMDA receptors and serotonergic/noradrenergic antidepressants in the forced swim test in mice. J Neural Transm. 2011; 118(11):1535-1546.

26. Kang S, Kim HJ, Kim HJ, et al. Effects of reboxetine and citalopram pretreatment on changes in cocaine and amphetamine regulated transcript (CART) expression in rat brain induced by the forced swimming test. Eur J Pharmacol. 2010;647(1-3):110-116. 
27. Porsolt RD, Anton G, Deniel M, Jalfre M. Behavioral despair in rats: a new model sensitive to antidepressant treatments. Eur J Pharmacol. 1978;47(4):379-391.

28. Lucki I. The forced swimming test as a model for core and component behavioral effects of antidepressant drugs. Behav Pharmacol. 1997; 8(6-7):523-532.

29. López-Rubalcava C, Lucki I. Strain differences in the behavioral effects of antidepressant drugs in the rat forced swimming test. Neuropsychopharmacology. 2000;22(2):191-199.

30. Page ME, Detke MJ, Dalvi A, Kirby LG, Lucki I. Serotonergic mediation of the effects of fluoxetine, but not desipramine, in the forced swimming test. Psychopharmacology (Berl). 1999;147(1):162-167.

31. Rénéric JP, Bouvard M, Stinus L. Idazoxan and 8-OH-DPAT modify the behavioral effects induced by either NA, or 5-HT, or dual NA/5-HT reuptake inhibition in the rat forced swimming test. Neuropsychopharmacology. 2001;24(4):379-390.

32. Renshaw PF, Parsegian A, Yang CK, et al. Lovastatin potentiates the antidepressant efficacy of fluoxetine in rats. Pharmacol Biochem Behav. 2009;92(1):88-92.

33. Haenisch B, Bönisch H. Depression and antidepressants: insights from knockout of dopamine, serotonin or noradrenaline re-uptake transporters. Pharmacol Ther. 2011;129(3):352-368.

34. Pruus K, Rudissaar R, Allikmets L, Harro J. The effect of the NMDA receptor antagonist dizocilpine on behavioral manifestations of serotonin and adrenergic antidepressants in rats. Methods Find Exp Clin Pharmacol. 2010;32(2):123-128.

35. Mori-Okamoto J, Namii Y, Tatsuno J. Subtypes of adrenergic receptors and intracellular mechanisms involved in modulatory effects of noradrenaline on glutamate. Brain Res. 1991;539(1):67-75.
36. Kirsch C, Eckert GP, Mueller WE. Statin effects on cholesterol microdomains in brain plasma membranes. Biochem Pharmacol. 2003;65(5): 843-856.

37. Mok SW, Thelen KM, Riemer C, et al. Simvastatin prolongs survival times in prion infections of the central nervous system. Biochem Biophys Res Commun. 2006;348(2):697-702.

38. Schoonjans K, Peinado-Onsurbe J, Fruchart JC, Tailleux A, Fiévet C, Auwerx J. 3-Hydroxy-3-methylglutaryl CoA reductase inhibitors reduce serum triglyceride levels through modulation of apolipoprotein C-III and lipoprotein lipase. FEBS Lett. 1999;452(3):160-164.

39. Selley ML. Simvastatin prevents 1-methyl-4-phenyl-1,2,3,6tetrahydropyridine induced striatal dopamine depletion and protein tyrosine nitration in mice. Brain Res. 2005;1037(1-2):1-6.

40. Vega GL, Weiner MF, Lipton AM, et al. Reduction in levels of 24Shydroxycholesterol by statin treatment in patients with Alzheimer disease. Arch Neurol. 2003;60(4):510-515.

41. Johnson-Anuna LN, Eckert GP, Keller JH, et al. Wood WG. Chronic administration of statins alters multiple gene expression patterns in mouse cerebral cortex. J Pharmacol Exp Ther. 2005;312(2): 786-793.

42. Kiss JP, Szasz BK, Fodor L, et al. GluN2B-containing NMDA receptors as possible targets for the neuroprotective and antidepressant effects of fluoxetine. Neurochem Int. 2012;60(2):170-176.

43. Machado-Vieira R, Ibrahim L, Henter ID, Zarate CA Jr. Novel glutamatergic agents for major depressive disorder and bipolar disorder. Pharmacol Biochem Behav. 2012;100(4):678-687.

44. Sanacora G, Treccani G, Popoli M. Towards a glutamate hypothesis of depression: an emerging frontier of neuropsychopharmacology for mood disorders. Neuropharmacology. 2012;62(1):63-77.
Neuropsychiatric Disease and Treatment

\section{Publish your work in this journal}

Neuropsychiatric Disease and Treatment is an international, peerreviewed journal of clinical therapeutics and pharmacology focusing on concise rapid reporting of clinical or pre-clinical studies on a range of neuropsychiatric and neurological disorders. This journal is indexed on PubMed Central, the 'PsycINFO' database and CAS.

\section{Dovepress}

The manuscript management system is completely online and includes a very quick and fair peer-review system, which is all easy to use. Visit http://www.dovepress.com/testimonials.php to read real quotes from published authors. 